\title{
Evaluating Connectivity between Marine Protected Areas Using CODAR High-Frequency Radar
}

\author{
Mark A. Moline 2 \\ California Polytechnic State Univ., \\ San Luis Obispo \\ Center for Coastal Marine Sciences \\ 1 Grand Ave., Bio. Sci. Dept. \\ San Luis Obispo, CA 93407 USA \\ Greg B. Crawford 3 \\ Humboldt State Univ. \\ 1 Harpst St., Dept. Oceanography \\ Arcata, CA 95521-8299 USA \\ Newell Garfield, III 4 \\ San Francisco State Univ. \\ Romberg Tiburon Center \\ 3152 Paradise Dr. \\ Tiburon, CA 94920 USA
}

\author{
Brian Zelenke $_{1}$ \\ California Polytechnic State University, San Luis Obispo \\ Center for Coastal Marine Sciences \\ 1 Grand Ave., Bio. Sci. Dept. \\ San Luis Obispo, CA 93407-0401 USA
}

\author{
Burt H. Jones 5 \\ Univ. of Southern California \\ 3616 Trousdale Parkway, AHF B-30 \\ Los Angeles, CA 90089-0371 USA \\ John L. Largier 6 \\ Univ. of California, Davis \\ Bodega Marine Laboratory \\ P.O. Box 247 \\ Bodega Bay, CA 94923 USA \\ Jeffrey D. Paduan 7 \\ Naval Postgraduate School \\ Code OC/Pd \\ Monterey, CA 93943 USA
}

\author{
Steven R. Ramp 8 \\ Monterey Bay Aquarium Research \\ Institute \\ 7700 Sandholdt Rd. \\ Moss Landing, CA 95039 USA \\ Eric J. Terrill, \\ Scripps Institution of Oceanography \\ 9500 Gilman Dr., SIO, UCSD \\ La Jolla, CA 92093 USA \\ Libe Washburn 10 \\ Univ. of California, Santa Barbara \\ Institute for Computational Earth \\ System Science \\ Ellison Hall 6818 \\ Santa Barbara, CA 93106-3060 USA
}

\section{ABSTRACT [revised]}

To investigate the connectivity between central California marine protected areas (MPAs), back-projections were calculated using the network of high-frequency (HF) radar ocean surface current mapping stations operated along the California coast by the member institutions of the Coastal Ocean Currents Monitoring Program with funding provided by California voters through Propositions 40 \& 50 and administered by the State Coastal Conservancy. Trajectories of $1 \mathrm{~km}$ resolution grids of water particles were back-projected from ten MPAs each hour, out through 40 days in the past, from each day in 2008, producing a map of where surface waters travel over a 40-day period to reach the MPAs - and visualizations of the length of time the waters travel along these paths. By comparing the travel times of those back-projected track-points that crossed between MPA regions, the connection time between MPAs along the State's central coast was assessed. Repeating these calculations resulted in a connectivity matrix between the MPAs in the region, and may be useful for assessing connectivity for the important invertebrate and fish larvae that are restricted to the surface ocean during a fraction of their lifecycle.

\section{INTRODUCTION}

The Marine Life Protection Act (MLPA) passed by the State of California in 1999 requires the design and management of a network of marine protected areas (MPAs) along California's coast with multiple aims, including (i) protection of the natural diversity and abundance of marine life, (ii) maintenance of the structure, function, and integrity of marine ecosystems, (iii) helping sustain, conserve, and protect marine life populations, including those of economic value, and (iv) rebuilding those that are depleted [1].

In redesigning its system of MPAs California has taken a regional approach, dividing the State's $1770 \mathrm{~km}$ coastline into five study regions (Fig. 1). As it is the only study region fully implemented at present, this investigation focused on the Central Coast MPA system which went into effect September 22, 2007. 


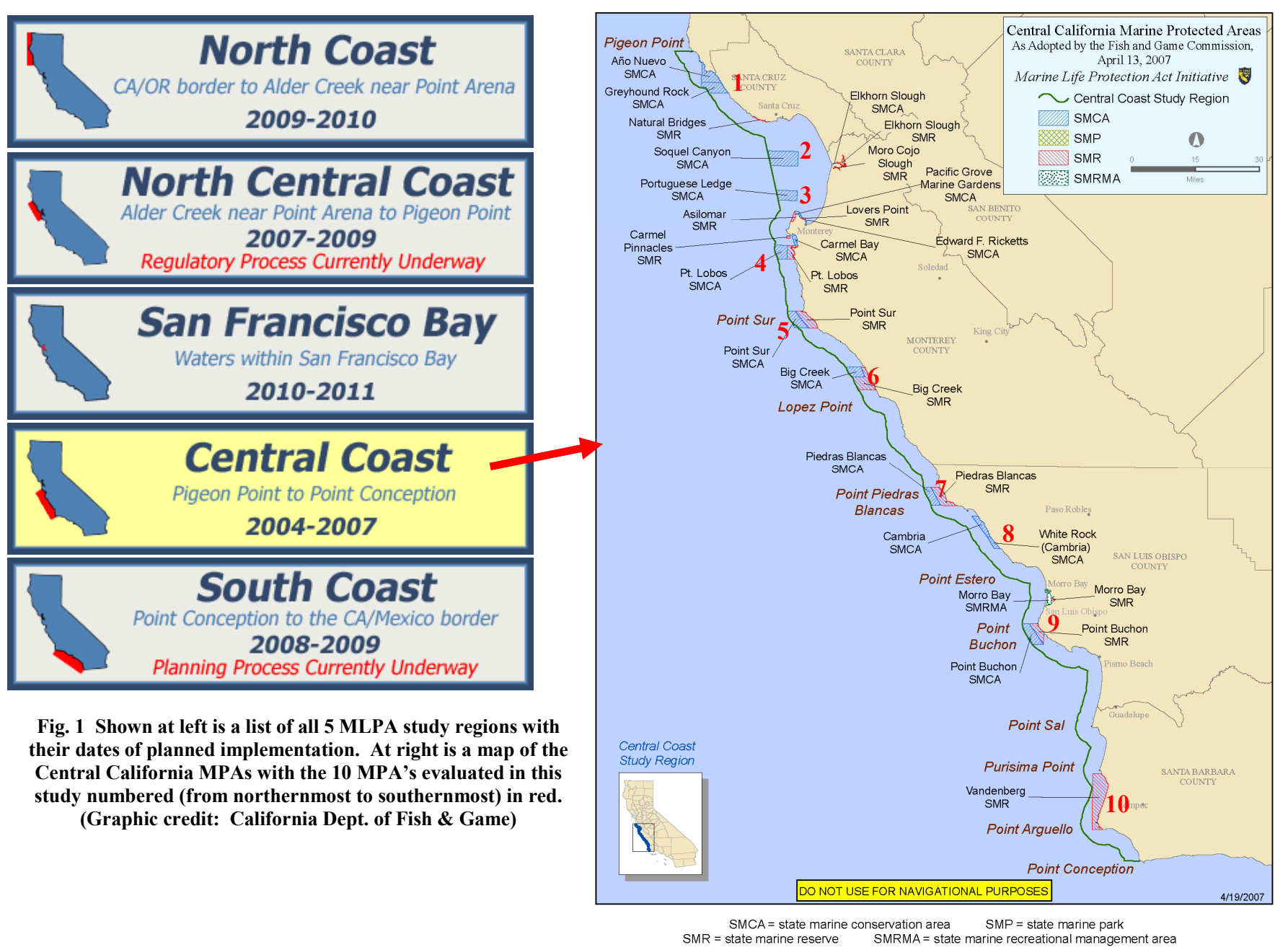

The MPLA calls for a program of adaptive management, monitoring, research, and evaluation - to assess the effectiveness and to adjust the management of the MPA network to achieve its goals. To this end the research presented here addresses a core technical challenge in evaluating MPAs: measuring their connectivity; specifically as it relates to assessment of the larval dispersal that links MPAs in a network. A key principal of the MLPA is spacing MPAs to promote connectivity through the transport of planktonic larvae or juveniles from one MPA to another. Planktonic larvae spawned within an MPA are known to disperse along the coast, entrained within the ocean's currents [2]. The length of time juveniles of a species spend in the water column, moving with the currents as planktonic larvae, before maturing and either settling to the bottom or growing strong enough to swim against the currents affects the likelihood that given fish or invertebrate larvae produced in one MPA will settle in another [3].

The spatial boundaries for MPAs must thus be chosen to help ensure that the species will persist, requiring knowledge of dispersal scales and patterns. This investigation provided estimates of surface current trajectories, analogous to likely dispersal paths of surface planktonic larval stages, between ten oceanic Central Coast MPA regions (from north to south): (1) Año Nuevo SMCA/Greyhound Rock SMCA, (2) Soquel Canyon SMCA, (3) Portuguese Ledge SMCA, (4) Pt. Lobos SMCA/SMR, (5) Pt. Sur SMCA/SMR, (6) Big Creek SMCA/SMR, (7) Piedras Blancas SMCA/SMR, (8) Cambria SMCA/White Rock SMCA, (9) Pt. Buchon SMCA/SMR, and (10) Vandenberg SMR. In this study currents were measured by the network of high-frequency (HF) radar ocean surface current mapping (SCM) systems operated along the California coast by the member institutions of the Coastal Ocean Currents Monitoring Program (COCMP) with funding provided by California voters through Propositions $40 \& 50$ and administered by the State Coastal Conservancy. Trajectories of a $1 \mathrm{~km}$ resolution grid of water particles were back-projected from the ten MPA regions each hour using the SCM data, out through 40 days in the past, from 366 starting-days in 2008, producing a map of where surface waters travel over a 40-day period to reach each MPA region - and a visualization of the length of time the waters travel along these paths. By comparing when waters last passed through other MPAs on their way to each of the ten MPA regions, the connection times between the MPAs were calculated. The result was a connectivity matrix between all ten MPA regions for the year 2008. 
The results derived show that the MPAs of the Central Coast study region are far from uniformly connected with the other study regions to the north and south proposed by the MLPA. Even within the Central Coast study region, its MPAs exhibit widely varying degrees of connectivity, with the trajectories of surface waters flowing into an MPA often not crossing through even directly adjacent MPAs. Significant directionality is observed in the transit of waters into the MPAs, pointing to the need for concepts of "average dispersal distance" to much more closely take into account each region's coastal physical oceanography in their application. The technique described by this investigation provides a tool for significantly improving MPA designers' ability to project the larval connectivity between specific designs of marine reserves.

\section{METHODS}

\section{A. Back-projections}

A back-projection model was developed to reverse-track the source-waters flowing to grids of points spaced $1 \mathrm{~km}$ apart within each MPA region for durations up through 40 days; a time period which would allow assessment for a range of larval durations. Trajectories were back-projected from the grid-points in each MPA region using the hourly $6 \mathrm{~km}$ and $2 \mathrm{~km}$ resolution SCM data measured by the COCMP's network of CODAR Ocean Sensors, Ltd. SeaSonde ${ }^{\mathbb{B}}$ HF-radars. The radiowave oceanography method employed by the HF-radars, described by [4], provided wide-area measurements of the ocean that would have been difficult or impossible to make any other way. The SCM data measured the complexities in the surface currents occurring upcoast, downcoast, within, and offshore of the MPAs that would have been missed using model results based on measured input from the sparse collection of current meters located tens, and in many areas hundreds, of kilometers apart off the California coast.

The year 2008 investigated in this study was selected to coincide with the time when coverage was maximized by the greatest number of HF-radars operating (Fig. 2). The ten MPA regions selected (Fig. 1) were those which fell significantly within the SCM coverage which began between $2-6 \mathrm{~km}$ offshore and typically extended seaward approximately $200 \mathrm{~km}$, measuring the surface currents to an effective depth of 1-2 m (Fig. 3). Directly adjacent SMCA and SMR MPA pairs were grouped together and considered as a single MPA region so that each region would have sufficient separation to allow differences in connectivity to be calculated.

A uniform grid of points spaced $1 \mathrm{~km}$ apart was created within the ten indentified MPA regions as starting locations for each day's back-projected trajectories (Fig. 4): (1) Año Nuevo inscribed 46 grid-points, (2) Soquel Canyon 71 grid-points, (3) Portuguese Ledge 33 grid-points, (4) Pt. Lobos 29 grid-points, (5) Pt. Sur 43 grid-points, (6) Big Creek 52 gridpoints, (7) Piedras Blancas 47 grid-points, (8) Cambria 20 grid-points, (9) Pt. Buchon 45 grid-

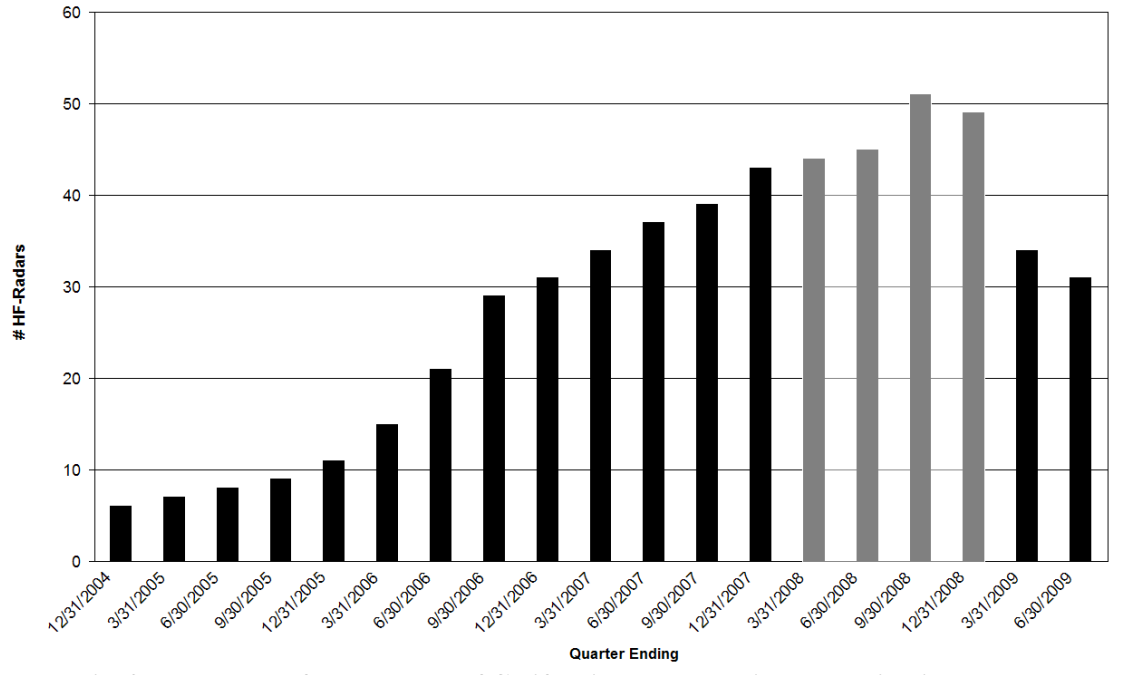

Fig. 2 Bar graph of the number of California HF-radar sites operating in each quarter with the four quarters of $\mathbf{2 0 0 8}$ from this study shaded grey. points, and (10) the Vandenberg MPA had 62 grid-points. In order to prevent bias in the results that would inhibit them from being applicable to any time-of-day, random starting hours between 0000 and 2300 were generated for each of the 366 days in 2008. Starting with the first hour generated on December 31, 2008, the velocity components from the SCM data (U, positive to east and V, positive to north) were linearly interpolated using the algorithm described in [5] to the $1 \mathrm{~km}$ resolution MPA grids to get an estimate of the surface current speed and directions at those exact locations. The sign of the U and V components were then reversed to calculate the location a water parcel (or presumably fish larva) would have originated from the hour before and been carried by the surface currents toward each grid-point. This process was repeated for each prior hour, through 40 previous days, interpolating the $\mathrm{U}$ and $\mathrm{V}$ components of velocity at each hour to the location calculated in the prior time-step and reversing sign to back-project the location the particle would have been the hour before.

Example: $\quad$ If the currents at a given location flowed south at a speed of $10 \mathrm{~cm} \mathrm{~s}^{-1}$ over the course of an hour ( 1 hour $=3600$ seconds), then the waters at that location would have been $360 \mathrm{~m}$ to the north the previous hour $\left(3600 \mathrm{~s} \times 10 \mathrm{~cm} \mathrm{~s}^{-1}=36,000 \mathrm{~cm}=360 \mathrm{~m}\right)$. 


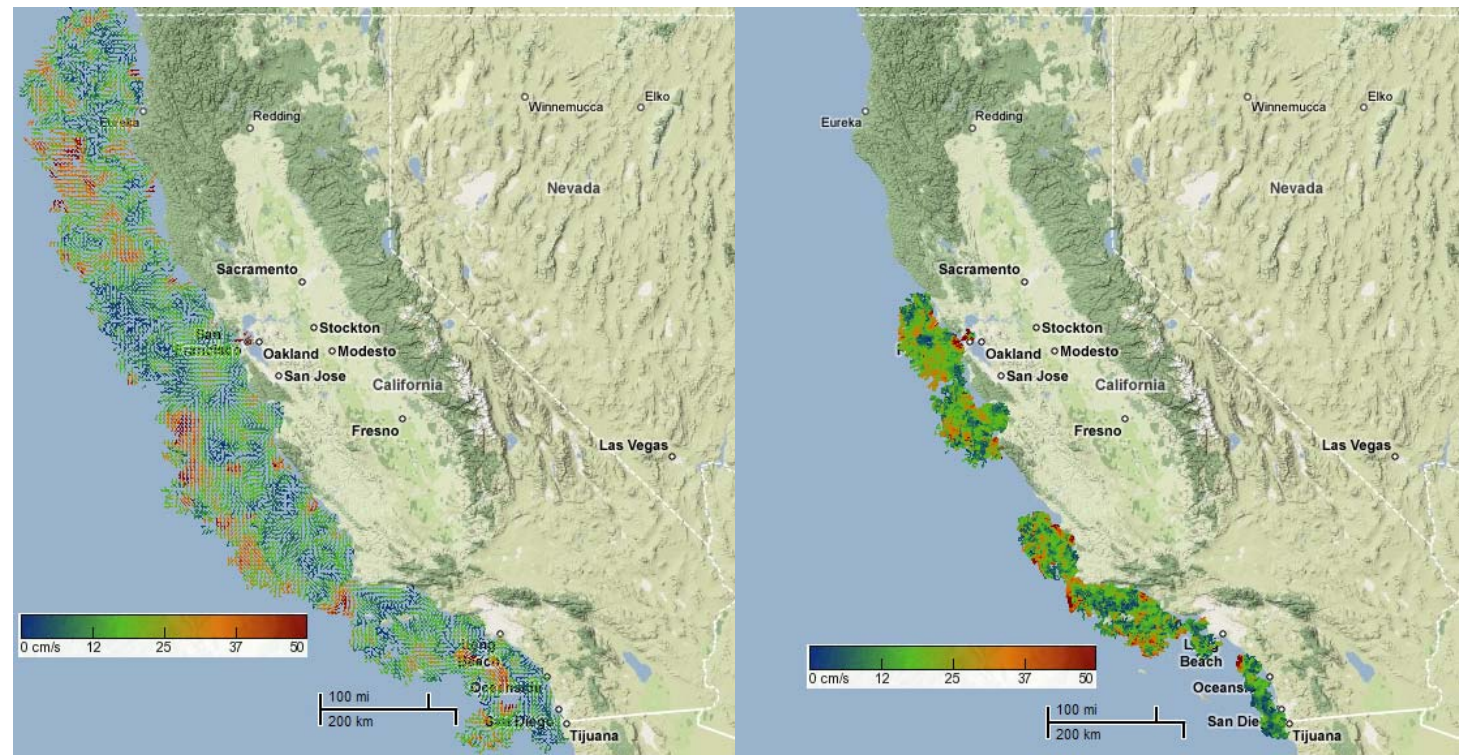

Fig. 3 Ocean surface currents measured off the coast of California at $6 \mathrm{~km}$ resolution in the left panel and at $2 \mathrm{~km}$ resolution in the right panel on October 28,2008 at 0000 UTC. The surface current vectors are shaded by velocity per the colorbars. The measurement coverage shown this hour was typical throughout 2008.

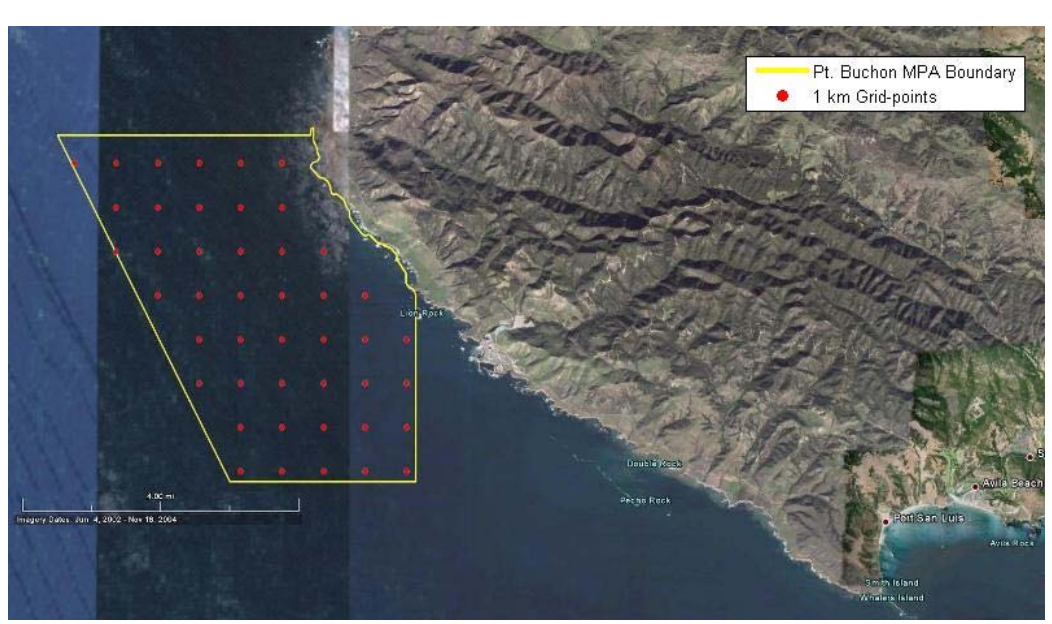

Fig. 4 The Point Buchon MPA region off the San Luis Obispo, California outlined in yellow. Inset within the Pt. Buchon MPA boundary are red circles at each of the 45 grid-points, spaced $1 \mathrm{~km}$ apart, from which the paths of the surface waters into the MPA were back-projected. The number of $1 \mathrm{~km}$ resolution grid-points falling within the boundaries of the MPA regions varied, with a high of 71 inset within the Soquel Canyon MPA region to a low of 20 in the Cambria MPA.

If trajectories progressed out of the area of SCM coverage, the measurements present that hour were extrapolated to those back-projected points via linear interpolation as described in [5]. In any instances where linear interpolation was unable to produce a result at a point (i.e., whenever a backprojected point fell outside the convex hull of the given hour's SCM data points), nearest-neighbor interpolation was instead used. If the backprojection of a particle caused its track to cross an island or coastal boundary, the distance the particle was projected to travel was applied first to the direction in $\mathrm{U}$. If land was still encountered the distance was then applied to the $\mathrm{V}$ direction. If both attempts to move the particle alongshore failed, it was held in position for that time-step and the process repeated the next hour, until the current moved the particle past or away from the shore.

Using the High Performance Computing Center (HPCC) at California Polytechnic State University, San Luis Obispo this process was repeated for each of the successive 366 days in 2008, calculating 430,080 back-projected positions each day for a grand total of 157,409,280 points for the entire year. The result was a total of 163,968 trajectories, each consisting of 960 hourly back-projected points ( 960 hours $=40$ days), along the paths of waters flowing towards the locations of the grid-points within each MPA region.

\section{B. Connectivity}

The connection times between MPAs were calculated by recording the most recent hour (up through 960 hours ago) each trajectory crossed each MPA border. Every grid-point within each MPA region had associated with it one back-projected trajectory for each day of the year in 2008, showing where the surface currents had traveled over 40 days to reach that spot, on that day. Using the HPCC the trajectories were considered individually; calculating the times, if any, they made intersections with the nine other MPA boundaries (self-intersections with the boundary of the destination MPA were ignored). Just a trajectory's most recent time of intersection with each of the nine other MPAs was retained, thereby determining how long it had been since those waters had last encountered each other MPA before reaching their destination. Repeating these calculations for each day of the year produced a database of the durations it took surface waters to flow from one MPA to another. 


\section{RESULTS}

In Table 1 are the mean number of days it took back-projections to travel from one MPA to reach another MPA. These results provide the average length of time it had been since surface waters entering an MPA had last been in each neighboring MPA. Naturally waters traveling to a given MPA passed through some neighboring MPAs more than others, and Table 2 shows what percentage of trajectories back-projected from an MPA crossed through each one of its neighbors. Table 2 thereby illustrates the degree of surface connectivity between each pair of MPAs.

A further examination of the connection times between the MPAs is given by Fig. 5. Rather than just the mean as in Table 1, these histograms show the percentage of the total intersections that occurred between each MPA pair within each 5, 10, 20, 30, and 40-day bin. Fig. 5 not only addresses what range of time surface waters in an MPA were last within each neighbor but, looking across a row or column, also shows how these distributions of connection times changed with alongshore distance, as the rows and columns are sorted in geographic order; northernmost to southernmost.

In Fig. 6 the stacked-bar histograms provide a quantitative visualization of how well connected each MPA was with its respective neighbors. The color coding of each bar by neighbor MPA shows the number of times trajectories of surface waters flowing toward the destination MPA transected the region given by the hue. Conversely, Fig. 7 shows, for the MPA in each panel, which other regions were best connected with it. Again, the histograms in Fig. 7 are colored by region; here showing how often the given MPA is crossed by surface waters flowing toward the tinted MPA.

Since the various MPA borders inscribed different numbers of starting $1 \mathrm{~km}$ gridpoints (Fig. 4), dividing the total number of trajectories back-projected through each other region, by the number of grid-points in the destination MPA, gave a measure of the "effectiveness per grid-point" at the destination MPA. These "number of intersections per grid-point, per MPA" are recorded in Table 3. Here, for example, despite having fewer grid-points from which to back-project trajectories the surface waters of the Cambria MPA did a better job of connecting to the Año Nuevo MPA (1.9 intersections with Año Nuevo MPA per grid-point) than did the waters of the larger Pt. Buchon MPA (0.1 intersections with Año Nuevo MPA per grid-point).

In order to quantify the effect size had on the degree of surface connectivity between MPAs, the calculations summarized in Table 4 were performed, where the number of intersections per square kilometer of shared surface area showed the impact between MPAs in proportion to their size.

The maps in Fig. 8 of the back-projected trajectories further help visualize these results by showing where the waters were $5,10,20$, 30 , and 40 days ago before reaching the given MPA. The density of the points plotted at these durations shows the impact of waters as sources to the MPA.

With the time-series of back-projections produced by the model for 2008, these data products could have been generated for any intra-annual time-period. This provides additional utility for exploring temporal influences such as seasonality.

TABLE 1.

MEAN NUMBER OF DAYS CONNECTING TRAJECTORIES TOOK TO INTERSECT THE MPA REGIONS GIVEN BY THE ROW HEADERS WHEN BACK-PROJECTED FROM THE MPAS PER THE COLUMN HEADERS. Back-projected from:

\begin{tabular}{|c|c|c|c|c|c|c|c|c|c|c|}
\hline $\begin{array}{l}\text { (Sorted north- } \\
\text { to-south) }\end{array}$ & \begin{tabular}{|c|} 
Año \\
Nuevo \\
\end{tabular} & \begin{tabular}{|c|} 
Soquel \\
Canyon
\end{tabular} & $\begin{array}{c}\text { Portuguese } \\
\text { Ledge }\end{array}$ & \begin{tabular}{|l|} 
Point \\
Lobos
\end{tabular} & $\begin{array}{c}\text { Point } \\
\text { Sur }\end{array}$ & \begin{tabular}{|c|} 
Big \\
Creek \\
\end{tabular} & \begin{tabular}{|l|} 
Piedras \\
Blancas
\end{tabular} & Cambria & \begin{tabular}{|c|} 
Point \\
Buchon
\end{tabular} & Vandenberg \\
\hline $\begin{array}{c}\text { Año } \\
\text { Nuevo }\end{array}$ & - & 16.7 & 13.2 & 14.1 & 19.6 & 22.4 & 23.8 & 24.3 & 24.0 & \\
\hline $\begin{array}{l}\text { Soquel } \\
\text { Canyon }\end{array}$ & 20.6 & - & 6.1 & 11.0 & 15.1 & 18.3 & 21.9 & 23.3 & 34.5 & \\
\hline $\begin{array}{l}\text { Portuguese } \\
\text { Ledge }\end{array}$ & 24.7 & 19.2 & - & 10.2 & 13.8 & 16.6 & 21.0 & 23.5 & 34.3 & \\
\hline $\begin{array}{l}\text { Point } \\
\text { Lobos }\end{array}$ & 23.8 & 22.2 & 18.2 & - & 8.0 & 11.5 & 17.7 & 20.9 & 30.7 & \\
\hline $\begin{array}{l}\text { Point } \\
\text { Sur }\end{array}$ & 25.3 & 25.2 & 22.0 & 14.3 & - & 7.5 & 15.3 & 16.6 & 23.2 & \\
\hline $\begin{array}{c}\text { Big } \\
\text { Creek }\end{array}$ & 30.0 & 22.9 & 26.0 & 23.5 & 18.4 & - & 12.5 & 20.8 & 22.6 & 36.2 \\
\hline $\begin{array}{l}\text { Piedras } \\
\text { Blancas }\end{array}$ & 29.4 & 28.3 & 28.8 & 23.7 & 20.0 & 16.2 & - & 10.0 & 22.0 & 37.7 \\
\hline Cambria & 24.6 & 23.2 & 25.0 & 30.1 & 27.2 & 25.8 & 13.2 & - & 16.3 & 25.2 \\
\hline $\begin{array}{l}\text { Point } \\
\text { Buchon }\end{array}$ & 35.8 & 35.9 & 36.4 & 35.1 & 30.4 & 26.6 & 21.2 & 23.9 & - & 20.7 \\
\hline Vandenberg & & & & & 37.3 & 35.6 & 26.5 & 27.1 & 25.8 & - \\
\hline
\end{tabular}

TABLE 2 .

PERCENTAGE OF TRAJECTORIES INTERSECTING THE MPA REGIONS GIVEN BY THE ROW HEADERS WHEN BACK-PROJECTED FROM THE MPAS PER THE COLUMN HEADERS. Back-projected from:

\begin{tabular}{|c|c|c|c|c|c|c|c|c|c|c|}
\hline $\begin{array}{c}\text { (Sorted north- } \\
\text { to-south) }\end{array}$ & \begin{tabular}{|c|} 
Año \\
Nuevo \\
\end{tabular} & $\begin{array}{l}\text { Soquel } \\
\text { Canyon }\end{array}$ & $\begin{array}{l}\text { Portugues } \\
\text { Ledge }\end{array}$ & \begin{tabular}{|l|} 
Point \\
Lobos
\end{tabular} & $\begin{array}{c}\text { Point } \\
\text { Sur }\end{array}$ & \begin{tabular}{|c|} 
Big \\
Creek \\
\end{tabular} & $\begin{array}{l}\text { Piedras } \\
\text { Blancas }\end{array}$ & Cambria & $\begin{array}{c}\text { Point } \\
\text { Buchon }\end{array}$ & Vandenberg \\
\hline $\begin{array}{c}\text { Año } \\
\text { Nuevo }\end{array}$ & - & 10.3 & 16.4 & 22.3 & 21.3 & 19.8 & 8.1 & 0.5 & 0.0 & 0.0 \\
\hline $\begin{array}{l}\text { Soquel } \\
\text { Canyon }\end{array}$ & 25.7 & - & 75.4 & 32.8 & 27.0 & 26.4 & 12.9 & 0.6 & 0.0 & 0.0 \\
\hline $\begin{array}{c}\text { Portuguese } \\
\text { Ledge }\end{array}$ & 11.2 & 55.6 & - & 38.3 & 29.9 & 30.2 & 12.0 & 1.4 & 1.0 & 0.0 \\
\hline $\begin{array}{l}\text { Point } \\
\text { Lobos }\end{array}$ & 11.1 & 28.6 & 29.0 & - & 65.0 & 54.2 & 23.9 & 3.2 & 2.0 & 0.0 \\
\hline $\begin{array}{l}\text { Point } \\
\text { Sur }\end{array}$ & 11.3 & 11.1 & 11.7 & 39.8 & - & 63.3 & 23.4 & 3.4 & 2.1 & 0.0 \\
\hline $\begin{array}{c}\text { Big } \\
\text { Creek }\end{array}$ & 4.6 & 6.3 & 7.8 & 16.5 & 20.1 & - & 22.4 & 6.2 & 2.4 & 0.0 \\
\hline $\begin{array}{l}\text { Piedras } \\
\text { Blancas }\end{array}$ & 3.4 & 3.6 & 3.7 & 8.0 & 17.8 & 19.1 & - & 15.0 & 4.6 & 0.1 \\
\hline Cambria & 1.2 & 2.1 & 3.0 & 13.0 & 18.4 & 21.4 & 35.9 & - & 19.6 & 2.1 \\
\hline $\begin{array}{l}\text { Point } \\
\text { Buchon }\end{array}$ & 0.3 & 0.6 & 0.7 & 0.9 & 3.5 & 3.0 & 15.7 & 30.4 & - & 7.9 \\
\hline Vandenberg & 0.0 & 0.0 & 0.0 & 0.0 & 0.1 & 0.2 & 3.3 & 6.4 & 13.8 & - \\
\hline
\end{tabular}




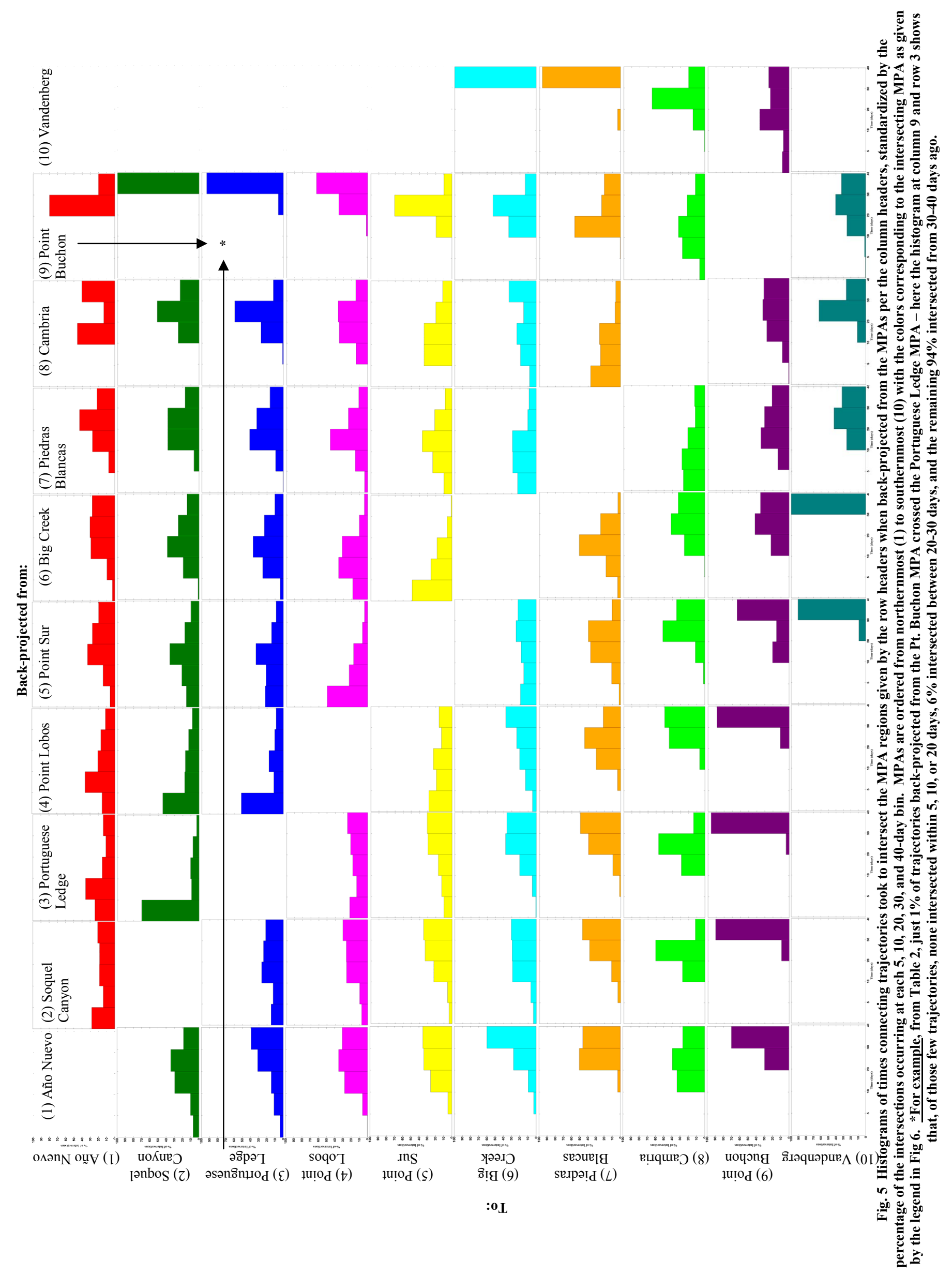




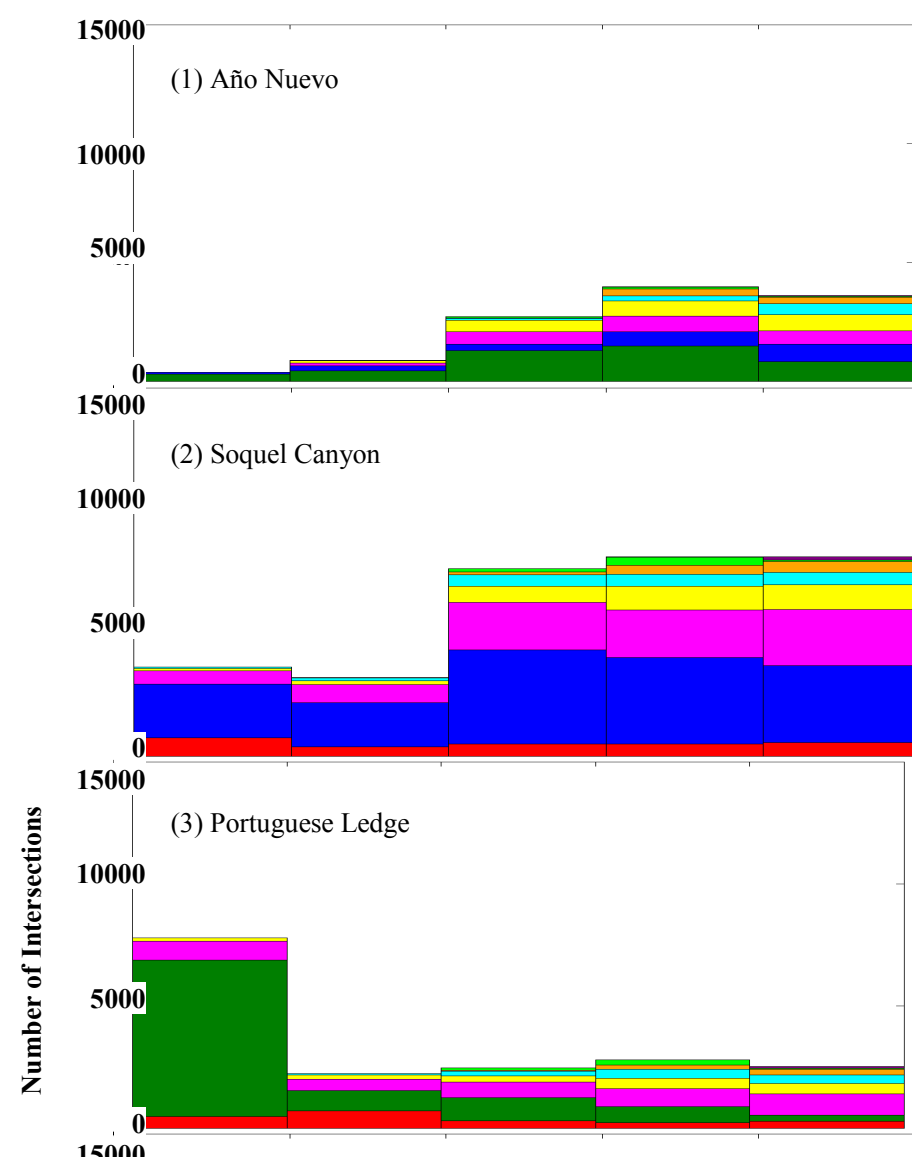

15000

(4) Point Lobos

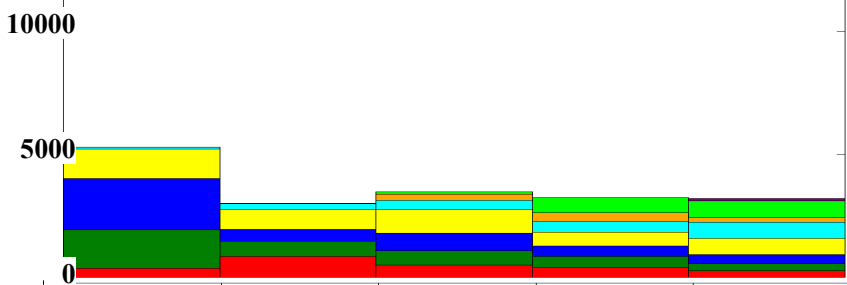

15000

(5) Point Sur

10000

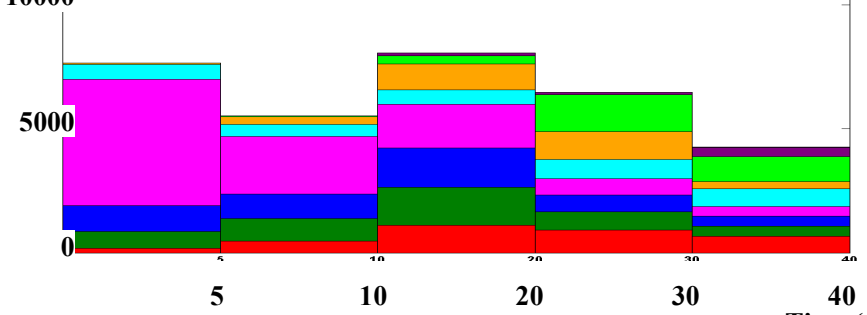

(6) Big Creek

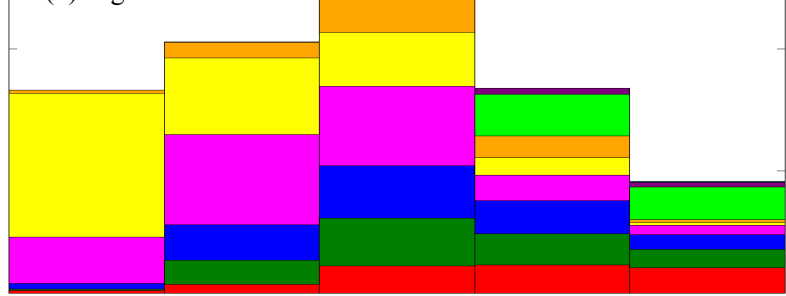

(7) Piedras Blancas

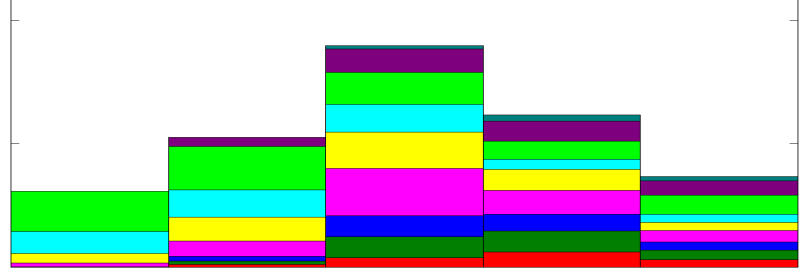

(8) Cambria
(9) Point Buchon$$
\text { * }
$$

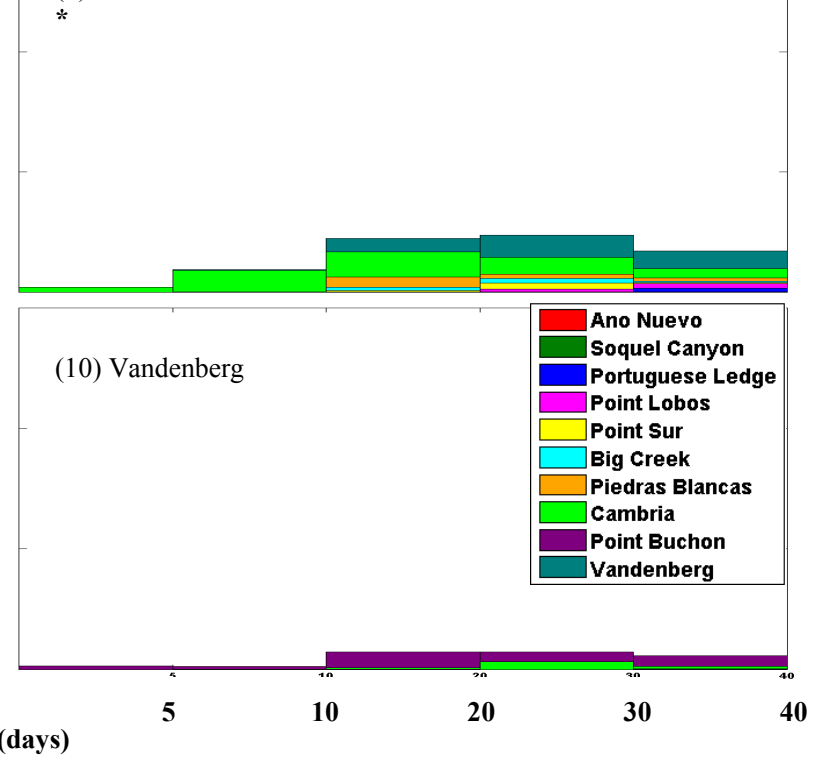

Fig. 6 Histograms of the times at which back-projections from each MPA region (panels \#1-10) first intersected other MPAs. In the bars plotted at the 5, 10, 20, 30, and 40-day bins, the fraction shaded by the unique color of the other MPAs, per the legend in panel \#10, shows the percentage of the total number of intersections with that MPA.

*Example: To answer the question, "How well connected was the Pt. Buchon MPA region?", comparing panel \#9 with the others shows that seven of the other MPAs had a greater number of intersections, with only the back-projections from the Cambria (\#8) and Vandenberg (\#10) MPAs crossing

through other MPAs less often. Still, the Pt. Buchon MPA experienced a maximum in connectivity between 20-30 days with 2,367 of its 7,466 intersections occurring within that time range - further, of those 2,367 intersections, the dominant width of the teal shading in that bin, relative to the $y$ axis, shows that the Vandenberg MPA accounted for most of those crossings, with 916 intersections. 


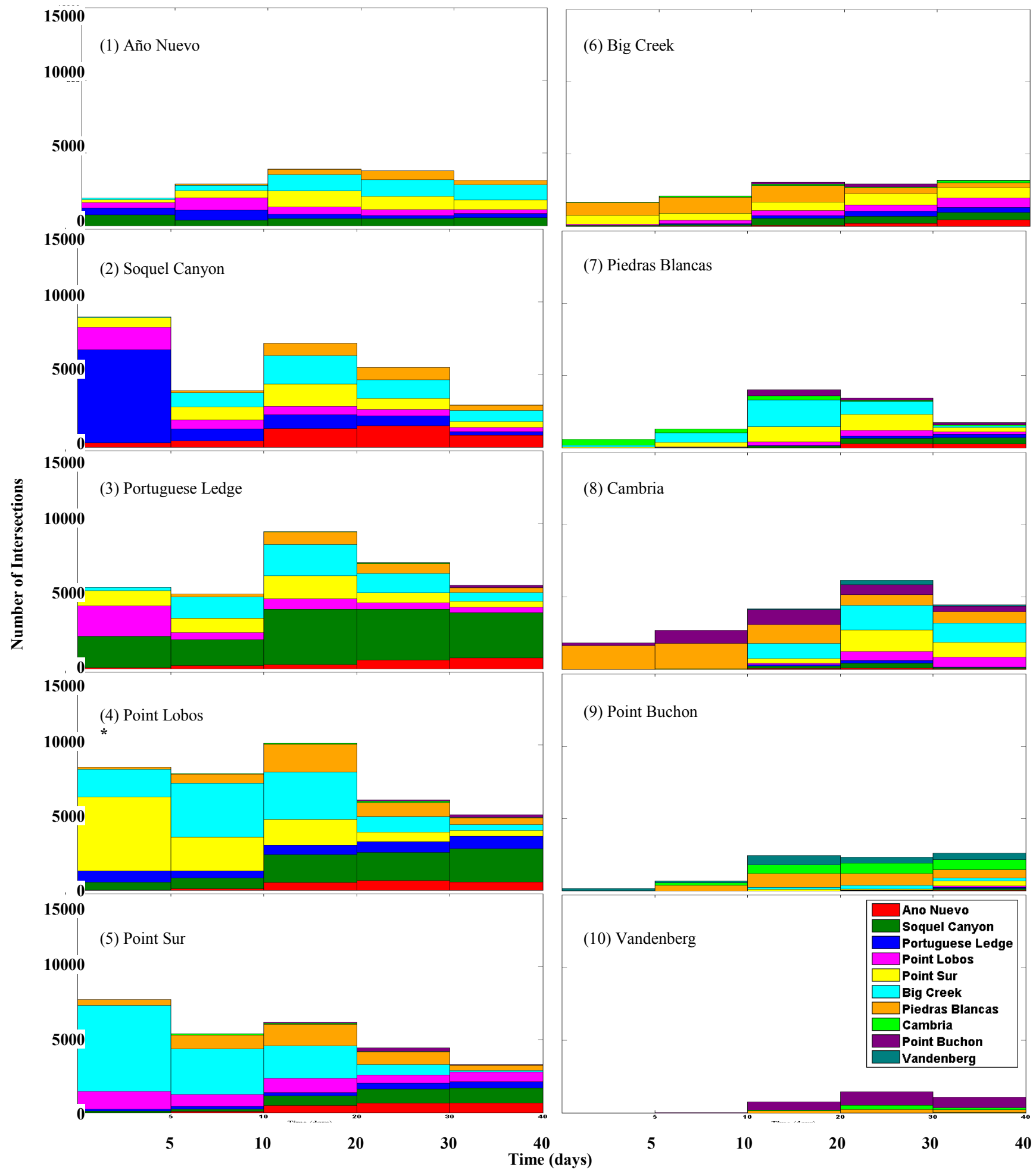

Fig. 7 Histograms of the times back-projections from other MPAs first intersected the MPA regions \#1-10. In the bars plotted at the 5, 10, 20, 30, and 40-day bins, the fraction shaded by the unique color of each other MPA (per the legend in panel \#10) shows the percentage of the total number of backprojections that intersected the given MPA from the colored MPA region.

*Example: To answer the question, "How well did other MPAs connect with the Point Lobos region?", comparing panel \#4 with the others shows that Pt. Lobos had the greatest number of intersections with 38,033 total; making Pt. Lobos the MPA most often crossed by waters flowing to the other MPAs. Most intersections with the Pt. Lobos MPA occurred between 10-20 days back (10,114), with waters that had the Big Creek MPA (cyan) as their destination (3,250 intersections) predominantly passing through in that time-window. 


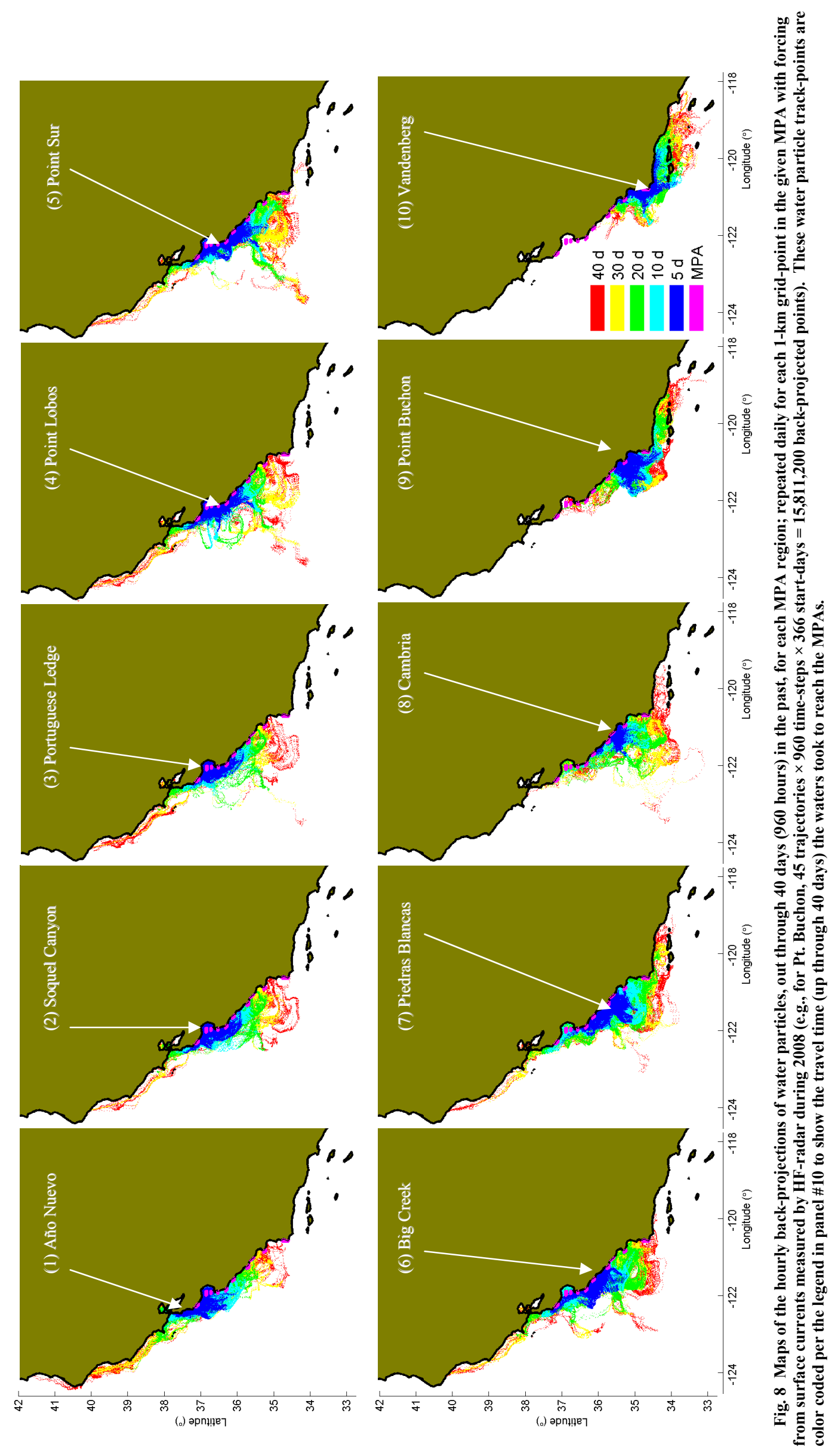




\section{DISCUSSION}

In this study there was a distinct separation in the surface flow north-to-south observed in the trajectories of the MPA's sourcewaters (Fig. 8). This points to a three-tier geographic classification between MPAs in the Central Coast study region (Fig. 1): those substantially connected to waters from the North Coast and North Central study regions (MPAs \#1-6), those whose sourcewaters span both the North and South Coast study regions (MPAs \#7-9), and the Vandenberg MPA (\#10) which was largely isolated from MPAs \#1-6, instead primarily incorporating waters from the South Coast study region.

An essential input to the MPA assessment and adaptive management as called for by the MLPA is ongoing data that will allow evaluation of how connectivity changes from year-to-year, helping to explain the role of environmental variability in observed increases and decreases of marine populations in designated reserves. Without recognition of this environmental variability, observed changes in populations may be falsely attributed to management decisions, resulting in misguided decisions on future management. With HF-radar SCM data and the model described, recommendations for MPA spacing can now be informed based on connectivity of the reserves through calculated pathways of larval transport.

The estimates derived here for trajectories into the MPAs could be improved for surface planktonic larvae by incorporating data into the model on larval behavior, population abundance, reproduction, and recruitment along with the HF-radar SCM measurements - important information that is missed by considering only the physical oceanography. MPAs need to be spaced with enough distance in-between to maximize the length of coastline replenished by the larvae produced within the reserves, yet close enough together to allow larvae to be exported from one MPA to the next. The model presented here, suitably applied, should significantly improve the chances that this will occur when incorporated into MPA planning.

\section{ACKNOWLEDGMENTS}

Our colleagues for their operation and maintenance of the HF-radar equipment which provided the 2008 SCM data including (in alphabetical order): Dan Atwater, Mike Cook, Tom Cook, Dan Elmore, Brian Emery, Julio César Figueroa González, Matt Gough, Chris Halle, Max Hubbard, Marcel Losekoot, Mark Otero, Jim Pettigrew, Matthew Ragan, Chris Raleigh, Laurie Roy, Deedee Shideler, and Shannon Stone. John W. Burdett for access to, and guidance in the use of, the HPCC at California Polytechnic State University. We especially thank the people of the State of California who, through Propositions 40 \& 50 with administration by the State Coastal Conservancy, funded the COCMP.

\section{REFERENCES}

[1] CAFGC (California Fish \& Game Code) Marine Life Protection Act., Div. 3, Ch. 10.5, §2850-2863, 1999.

[2] Shanks, A.L., Grantham, B.A. \& Carr, M.H. Propagule dispersal distance and the size and spacing of marine reserves. Ecological Applications, 13, S159-S169, 2003.

[3] Shanks, A. L. Pelagic larval duration and dispersal distance revisited. Biol. Bull., 216, 373-385, 2009.

[4] Lipa, B. J., and D. E. Barrick, Leastsquares methods for the extraction of surface currents from CODAR cross-loop data: Application at ARSLOE. IEEE J. Oceanic Eng., OE-8, 226-253, 1983.

[5] Barber, C. B., D.P. Dobkin, and H.T. Huhdanpaa. The Quickhull Algorithm for Convex Hulls. ACM Transactions on Mathematical Software, Vol. 22, No. 4, 469-483, 1996.

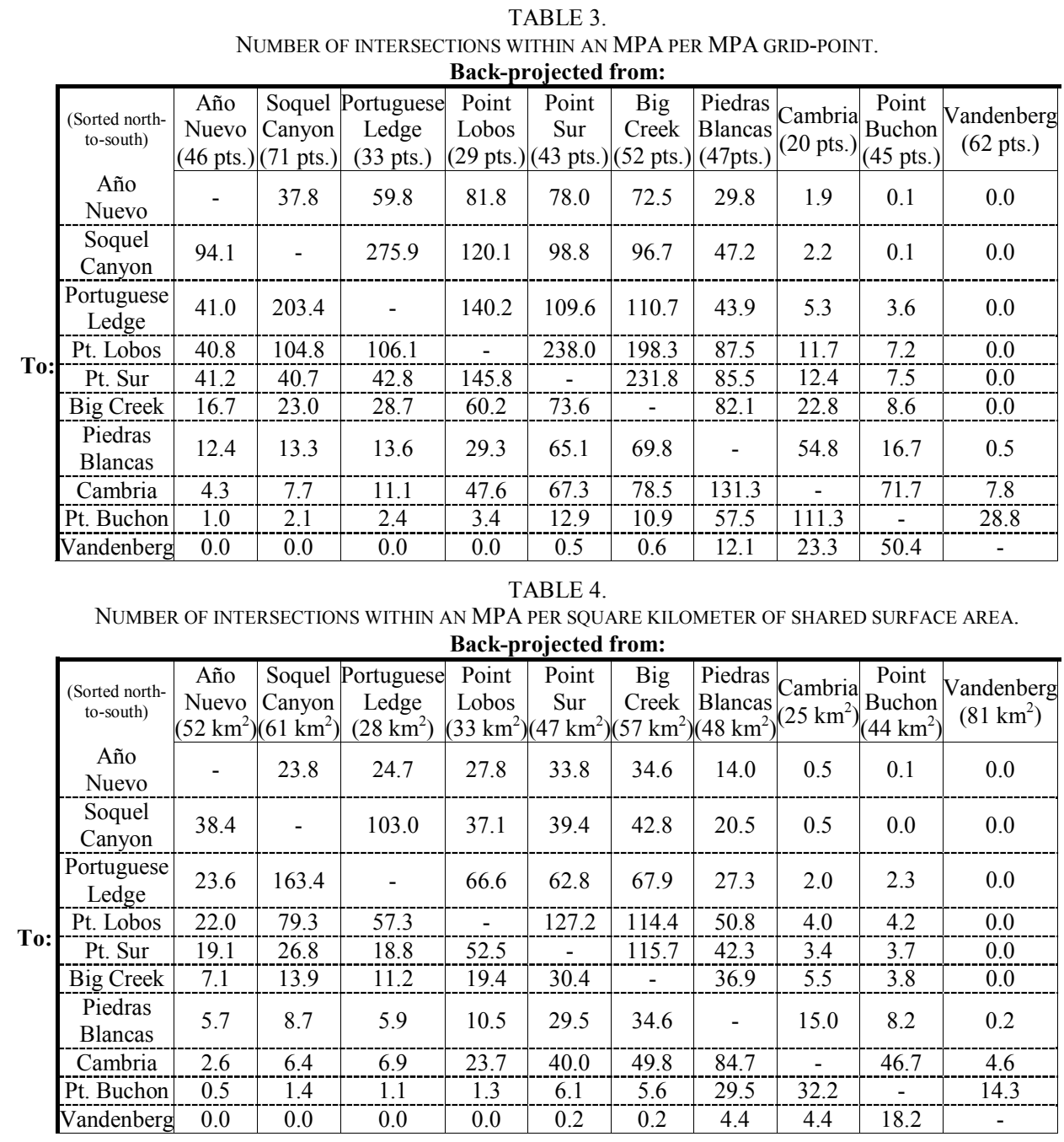

